\title{
Intestinal parasitism in schoolchildren in 2005, 2006 and 2007: A real challenge to overcome by the national deworming campaign in Northwestern Mexico
}

\author{
Luis Quihui Cota*, Gloria Guadalupe Morales-Figueroa
}

Department of Public Health and Nutrition, Research Center for Food and Development, Hermosillo, Mexico;

"Corresponding Author: lquihui@,ciad.mx, lmorales@ciad.mx

Received 13 January 2013; revised 7 March 2013; accepted 15 April 2013

Copyright (C) 2013 Luis Quihui Cota, Gloria Guadalupe Morales-Figueroa. This is an open access article distributed under the Creative Commons Attribution License, which permits unrestricted use, distribution, and reproduction in any medium, provided the original work is properly cited.

\begin{abstract}
Introduction: Intestinal parasitism has been a challenge to overcome for the Mexican deworming campaign and this study determined the prevalence of these infections in schoolchildren treated with albendazole in Northwestern Mexico. Methods: Study sites in marginal conditions, with gastrointestinal infections and albendazole intervention were selected. The Faust and Kato Katz techniques were used to identify the parasites spp. and the NCSS software was used for statistical analysis. Results: A total of 450,389 and 364 schoolchildren participated in 2005, 2006, and 2007 respectively during this study. The mean age was $7.9( \pm 1.3)$. The estimated prevalences were of $42 \%, 30 \%$ and $37 \%$ for protozoa infections, and $11 \%, 12 \%$ and $11 \%$ for helminth infections in 2005, 2006 and 2007 respectively. Conclusion: The education strategies should be integrated into the Mexican deworming campaign.
\end{abstract}

Keywords: Intestinal Parasitism; Albendazole; Deworming Campaign; Schoolchildren;

Northwest Mexico

\section{INTRODUCTION}

Intestinal parasitism has been recognized as a public health problem worldwide [1,2], because they are associated with malabsorption and growth disturbances $[3,4]$. Intervention programs have been introduced for the control of parasitic helminth infections and they have significantly reduced their prevalence, intensity and mor- bidity using mebendazole and albendazole [5]. In Mexico, these infections remain a public health problem in the population [6]. In 1987, Mexican schoolchildren were considered the most vulnerable group to these infections, and 35.2 and 83.2 million Mexicans were affected by helminths and protozoa, respectively [7]. This motivated the launch of a deworming campaign in 1993 influenced by the effectiveness of global programs for control of helminths; the recommendation by the World Health Organization; the political will of the Mexican government; and the infrastructure provided by the Health National Week [8]. The Ministry of Health determined that albendazole was provided to $95 \%$ of children (6 - 14 years old) to reduce the prevalence and excretion of helminth eggs, and re-infection and morbidity rates [8]. Chemically, the albendazole is methyl 5-(propylthio)-2benzimidazolecarbamate and its molecular formula and weight are $\mathrm{C} 12 \mathrm{H} 15 \mathrm{~N} 3 \mathrm{O} 2 \mathrm{~S}$ and 265.34 respectively, and binds to tubulin preventing the formation of microtubules and cell division resulting in impairment of nutrient uptake by the parasite [5]. Between 1993 and 1998 the program reduced the prevalence of Ascaris lumbricoides and Trichuris trichiura from $20 \%$ to $8 \%$ and $15 \%$ to $11 \%$, respectively [8] in more than 90,000 Mexican children. In 1995, the prevalence of Giardia duodenalis was estimated at $32 \%$ in Mexico [9] and remained the most important protozoan infection (14\% to $49 \%$ ) in northwestern Mexico [10,11]. Entamoeba histolytica is another protozoan pathogen with prevalence up to $50 \%$ in southern Mexico [12] but appears to be less prevalent than giardiasis in northwestern Mexico [10,11,13-15]. Currently, the Ministry of Health continues to administer a single dose of $400 \mathrm{mg}$ twice a year of albendazole to schoolchildren in Mexico, but the intestinal parasites are 
recognized to contribute to morbidity of the general population of northwestern Mexico [13]. Therefore, the aim of this study was to investigate the current prevalence of intestinal parasites in children who are receiving periodically albendazole in northwest Mexico.

\section{METHODS}

This cross-sectional study was conducted in September 2005, September 2006 and April 2007 in Sonora (northwest Mexico). Sonora is bordering to the east with the state of Chihuahua, south to the state of Sinaloa, west to the Gulf of California, and north to the U.S. state of Arizona. The summer average temperature is $38^{\circ} \mathrm{C}$ (June to August) and from $5^{\circ} \mathrm{C}$ to $30^{\circ} \mathrm{C}$ in winter (September to January). In 2005, the total population of Sonora was estimated in 662,000 and $60 \%$ of this was under 15 years of age [16]. Ten public primary schools of 3 municilities of Sonora were selected in suburban and rural areas based on high gastrointestinal infection rates in the population [13]: low socioeconomic status in the areas around the schools [17] and administration of twice a year for a single dose (400 $\mathrm{mg}$ ) of albendazole by the national deworming campaign [8]. Up to date, no epidemiological surveillance to investigate the prevalence of intestinal parasitic infections has been conducted in Northwestern Mexico. A total of 3387 schoolchildren were officially enrolled in the schools selected from September 2005 to June 2007 [18]. The purpose of this study was described to the personnel of health services, municipalities, schools, parents and schoolchildren. All children were invited to participate while three plastic containers per child were distributed for stool collection. Only $1203(35 \%)$ of the total of 3387 children participated in the 3 sampling periods. Administration of albendazole by the deworming campaign was confirmed by the school personnel.

A written consent was obtained from parents or guardians of the 1203 participating children. Of the remaining 1313 from the total 3387 enrolled schoolchildren, 1159 were unwilling to participate and 154 did not meet the study criteria (disabled, supplemented or medicated). Approval to conduct this study was granted by the Ethical Review Committee of the Research Center for Food and Development. If required, infected children received the proper treatment by the Ministry of Public Health.

Stool samples were collected and transported to the Research Center for Food and Development. Samples were stored at $5^{\circ} \mathrm{C}$ and $7^{\circ} \mathrm{C}$ for $24-72$ hours prior to analysis by the techniques of Faust and Kato-Katz [19]. Faust was used for identification of protozoan cysts of $G$. duodenalis (Figure 1), Entamoeba histolytica (Figure 2), Entamoeba dispar, Entamoeba moshkovskii [20], Enta- moeba coli, Endolimax nana and Iodamoeba butschlii and helminth eggs of $A$. lumbricoides, $T$. trichiura and $H$. nana (Figure 3). Kato-Katz was used to count the number of eggs per gram of feces (epg) of helminth infections (defined as intensity of infection) using the 40x objective, and the final value was the average of epg divided per the number of samples (3.2 or 1) provided per child. The epg was calculated by multiplying twenty

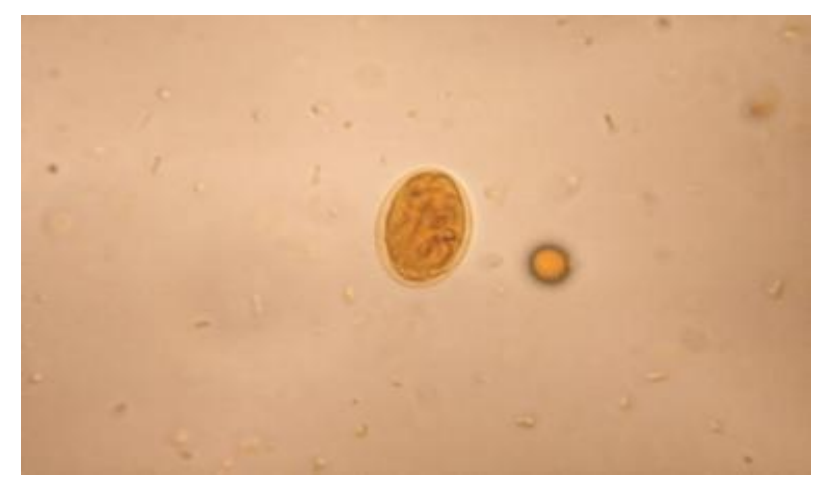

Figure 1. G. lamblia. Immature binucleated infective cyst stained in iodine $(40 \times)$.

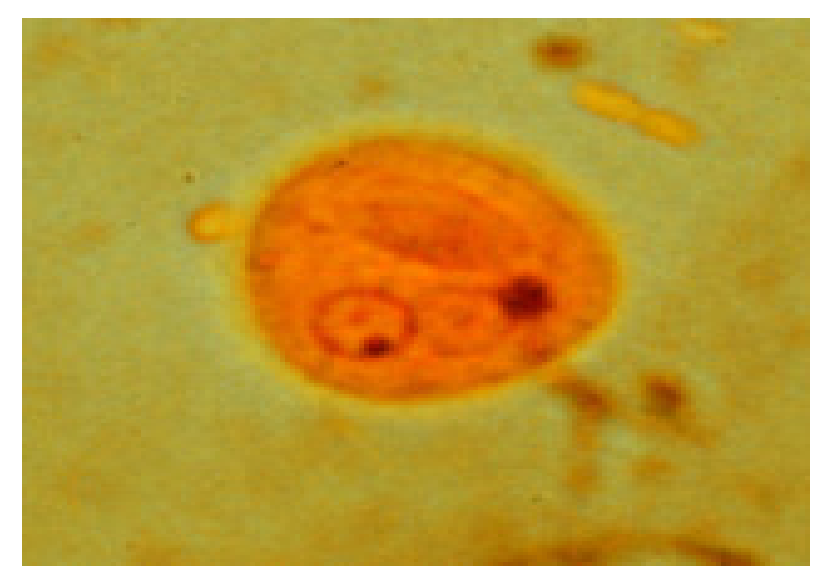

Figure 2. E. histolytica. Mature 2 visible nuclei infective cyst iodine-stained $(40 \times)$.

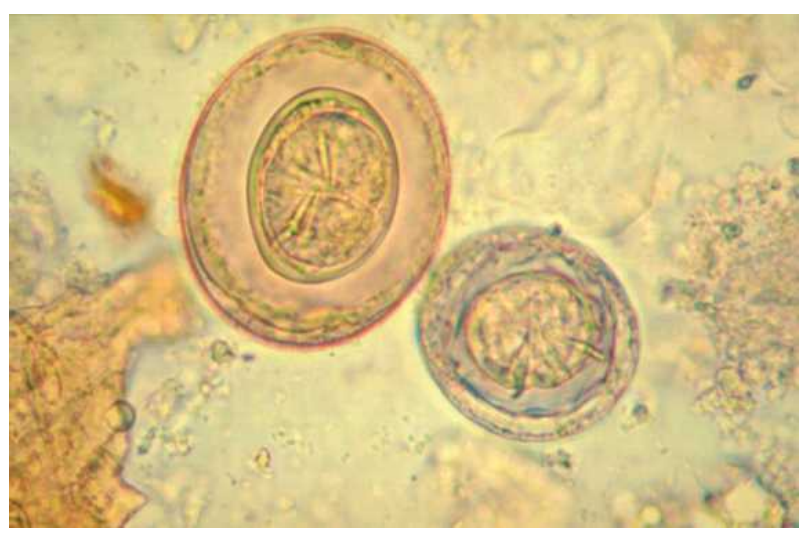

Figure 3. H. nana. An inner membrane with two poles and polar filaments spread out between the two membranes $(40 \times)$. 
times the number of eggs counted in $50 \mathrm{mg}$ of feces. Infection was defined as the state with one or more species of parasites, poliparasitism with two or more species of parasites, helminth infection only with species of helminth parasites, protozoa infections only species of protozoan parasites.

The prevalence of intestinal parasitism was the percentage of children with parasites spp. in any of the fecal samples provided. The Fisher test was used to test the difference between proportions (prevalence of parasites spp.). The intensity of infection with helminth species was expressed as a median with confidence interval and Kruskal Wallis to test the difference between the ageintensity data (epg). Data were analyzed using the Number Crunching Statistical System 2007, Version 1.6.0. (Utah 84037.com.USA). P-values $<0.05$ were considered as statistically significant.

\section{RESULTS}

A total of 450, 389 and 364 children participated in September 2005, September 2006 and April 2007 respectively. The mean ages were $7.7( \pm 1.2), 8.1( \pm 1.3)$ and $7.9( \pm 1.3)$ in the 3 sampling periods. $220(49 \%), 217$ (56\%) and 199 (55\%) were girls in 2005, 2006 and 2007 respectively. No differences were found between the proportions of boys and girls $\left(\chi^{2}=2,342, \mathrm{df}=1, \mathrm{P}=\right.$ 0.7003 in $2005 ; \chi^{2}=3.476, \mathrm{df}=1, \mathrm{P}=0.6231$ in 2006 and $\chi^{2}=1.936$, $\mathrm{df}=1, \mathrm{P}=0.1455$ in 2007). The overall prevalence of intestinal parasites between boys and girls was $48 \%$ vs. $44 \%(\mathrm{P}=0.708)$ in $2005 ; 29 \%$ vs. $35 \%(\mathrm{P}=$ $0.357)$ in 2006 ; and $41 \%$ vs. $42 \%(\mathrm{P}=0.8466)$ in 2007. In addition, no difference was found between the prevalences of parasites spp. by gender (data not shown). A total of 1231, 861 and 890 fecal samples were collected in September 2005, September 2006 and April 2007 respectively. $62 \%$ and $26 \%$ of the children provided 3 and 2 stool samples in September 2005; 47\% and 26\% provided 3 and 2 samples in September 2006; and 63\% and 19\% provided 3 and 2 stool samples in April 2007. High prevalences for intestinal parasitic infections, and protozoa infections were found in 2005, 2006 and 2007 respectively (Table 1). H. nana and G. duodenalis also showed important prevalences. E. histolytica/disparl moshkovskii showed a low prevalence in all sampling periods. Helminth infections by A. lumbricoides, $T$. trichiura and hookworms were not detected in this study.

The prevalence of intestinal parasites showed an increasing trend with age (group 6 - 7.9 vs. group 8 - 9.9, $\mathrm{P}=0.2796$, and group $6-7.9$ vs. group $10-11, \mathrm{P}=$ 0.2773 in 2005; group $6-7.9$ vs. group $8-9.9, \mathrm{P}=$ 0.8770 , and group $6-7.9$ vs. group $10-11, P=0.6631$ in 2006; and group 6 - 7.9 vs. group $8-9.9, \mathrm{P}=0.2284$, and group $6-7.9$ vs. group $10-11, P=0.2282$ in 2007) (Table 2).

During the study, 50 of 450 (September 2005), 42 of 389 children (September 2006), and 41 of 364 (April

Table 1. Prevalence of intestinal parasites in 1203 schoolchildren of 10 primary schools during 3 sampling periods in northwestern Mexico.

\begin{tabular}{|c|c|c|c|c|c|c|}
\hline \multirow{3}{*}{$\begin{array}{c}\text { Sampling time } \\
\text { Number of children }\end{array}$} & \multicolumn{2}{|c|}{ September 2005} & \multirow{2}{*}{\multicolumn{2}{|c|}{$\begin{array}{c}\text { September } 2006 \\
\text { Prevalence (\%) }\end{array}$}} & \multicolumn{2}{|c|}{ April 2007} \\
\hline & & & & & & \\
\hline & \multicolumn{2}{|c|}{450} & \multicolumn{2}{|r|}{389} & \multicolumn{2}{|r|}{364} \\
\hline & $\mathbf{n}$ & $\%(\mathrm{CI})$ & $\mathbf{n}$ & $\%(\mathrm{CI})$ & $\mathbf{n}$ & $\%(\mathrm{CI})$ \\
\hline Infection & 207 & $46.0(41-51)$ & 136 & $35.0(32-38)$ & 152 & $42.0(37-47)$ \\
\hline Poliparasitism & 87 & $20.0(16-23)$ & 70 & $18.0(13-21)$ & 81 & $22.0(18-27)$ \\
\hline Helminthiases & 55 & $11.0(9-15)$ & 47 & $12.0(10-14)$ & 41 & $11.0(8-15)$ \\
\hline Protozoasis & 187 & $42.0(37-46)$ & 117 & $30.0(37-46)$ & 134 & $37.0(32-42)$ \\
\hline Hymenolepis nana+ & 55 & $11.0(9-15)$ & 47 & $12.0(10-14)$ & 41 & $11.0(8-15)$ \\
\hline Entamoeba histolytica/dispar/moshkovskii $\Delta$ & 28 & $6.0(4-9)$ & 15 & $4.0(2-5)$ & 23 & $6.0(4-9)$ \\
\hline Giardia duodenalis + & 107 & $24.0(20-28)$ & 78 & $20.0(17-23)$ & 70 & $19.0(15-24)$ \\
\hline Endolimax nana- & 68 & $15.0(12-19)$ & 39 & $10.0(7-13)$ & 91 & $25.0(21-30)$ \\
\hline Entamoeba coli- & 62 & $14.0(11-17)$ & 74 & $19.0(15-23)$ & 51 & $14.0(11-18)$ \\
\hline Iodamoeba butschlii- & 20 & $5.0(3-7)$ & 12 & $3.0(1-5)$ & 8 & $2.0(1-4)$ \\
\hline
\end{tabular}

CI: Confidence interval at 95\%; +: Pathogens; -: No pathogens; $\Delta$ : E. histolytica is pathogen and E. dispar and E. moshkovskii are no pathogens (These species were not confirmed in this study). 
Table 2. Prevalence of intestinal parasites by age group in 1203 schoolchildren of 10 public primary schools during 3 sampling periods in northwest Mexico.

\begin{tabular}{|c|c|c|c|c|c|c|c|c|c|c|c|c|}
\hline & \multicolumn{4}{|c|}{ September 2005} & \multicolumn{4}{|c|}{ September 2006} & \multicolumn{4}{|c|}{ April 2007} \\
\hline \multicolumn{13}{|c|}{ Prevalence (\%) } \\
\hline \multirow{2}{*}{$\begin{array}{c}\text { Age } \\
\text { Years }\end{array}$} & \multicolumn{2}{|r|}{ Infected } & \multicolumn{2}{|c|}{ No infected } & \multicolumn{2}{|r|}{ Infected } & \multicolumn{2}{|c|}{ No infected } & \multicolumn{2}{|r|}{ Infected } & \multicolumn{2}{|c|}{ No infected } \\
\hline & $\mathbf{n}$ & $\%(\mathrm{CI})$ & $\mathbf{n}$ & $\%(\mathrm{CI})$ & $\mathbf{n}$ & $\%(\mathrm{CI})$ & $\mathbf{n}$ & $\%(\mathrm{CI})$ & $\mathbf{n}$ & $\%(\mathrm{CI})$ & $\mathbf{n}$ & $\%(\mathrm{CI})$ \\
\hline $6-7.9$ & 94 & $42.0(35-48)$ & 132 & $58.0(52-65)$ & 50 & $32.0(25-40)$ & 106 & $68.0(60-75)$ & 54 & $35.0(28-44)$ & 98 & $65.0(56-72)$ \\
\hline $8-9.9$ & 96 & $50.0(42-57)$ & 90 & $50.0(39-61)$ & 62 & $34.0(27-41)$ & 120 & $66.0(59-73)$ & 79 & $47.0(38-53)$ & 94 & $54.0(47-62)$ \\
\hline $10-11.9$ & 21 & $55.0(38-71)$ & 17 & $45.0(29-62)$ & 22 & $39.0(20-50)$ & 29 & $66.0(50-80)$ & 19 & $49.0(32-65)$ & 20 & $51.0(35-68)$ \\
\hline
\end{tabular}

CI: Confidence interval.

2007), excreted a median of 520, 630 and 820 epg of $H$. nana respectively. From these children, $16(32 \%)$ and 16 (32\%) children in 2005, $20(48 \%)$ and $8(19 \%)$ in 2006, and $4(5 \%)$ and $19(26 \%)$ in 2007 showed intensities $\leq 100$ and $\geq 1000$ epg respectively. The intensity of infection with $H$. nana showed a tendency of increasing with age in this study (Table 3).

\section{DISCUSSION}

Almost half of our children were suffering from intestinal parasites. Previous local publications considered to G. duodenalis to be the predominant pathogenic protozoan $[11,12,15]$ and $H$. nana followed by T. trichiura and A. lumbricoides as the most important helminth species in northwest Mexico. Our study confirmed that $G$. duodenalis is the predominant protozoan species and H. nana as unique helminth detected in the study sites. Before the Mexican campaign (1993), prevalences of $58.9 \%$ in 1957 and $19.5 \%$ in 1968 for ascariasis [21] and prevalences of $39.7 \%$ in 1957 and $19.5 \%$ in 1978 for trichuriasis were published in Mexico [22, 23]. Similarly, the prevalence of giardiasis and amibiasis ranged from $14 \%$ to $16 \%$ and $12 \%$ to $21 \%$, respectively from 1982 to 1984 in children under 15 years of age in different Mexican regions [24-26]. After 1993 [27-30], the prevalences of T. trichiura, A. lumbricoides, H. nana, G. duodenalis and E. histolytica were peaking around $16 \%, 8 \%, 15 \%, 24 \%$ and $60 \%$ respectively in the general population. This revealed a substantial reduction of trichuriasis and ascariasis, but a persistent giardiasis, hymenolepiasis and amebiasis in Southern Mexico. Probably this pattern was associated with the national deworming campaign and this may explains the absence of ascariasis and trichuriasis in our study. Furthermore, no differences were found in the prevalence of intestinal infections between boys and girls. Studies in Mexico and other Latin American countries have found similar findings probably due to similar transmission risk activities related to poor hygiene between genders [31]. On the other hand, the prevalence of intestinal parasites showed an increasing trend with age in our study. Khosrow, et al. [32], published a similar finding in 405 Iranian schoolchildren (6 to 10 years) without identifying the risk factors. This probably reflects the major attention from parents to younger children that may favor that older children are more easily infected. It is also probable, the higher the prevalence of H. nana, the greater its intensity in this study. In spite of the deworming campaign, the persistence of these infections may be a reflection of poverty, clean water supplies and poor hygiene practices of our children's families. This study is not evaluating the effectiveness of the deworming campaign, due to inappropriate sample size and lack of a methodological strategy of sampling. Nevertheless, we recognized that the Mexican campaign is aimed primarily at the soil-transmitted helminthiasis and albendazole is the drug of choice. However, a passive attitude should not be taken by the authorities meanwhile our study site's population is at high risk of acquiring giardiasis and hymenolepiasis. Our schoolchildren had received albendazole in April 2005, April 2006 and October 2006. This suggested that health education strategies should be integrated into the deworming campaign and decision-makers should improve the quality of basic services provided to the study sites, since albendazole alone will not improve health conditions of our study children.

\section{CONCLUSION}

This study provided data on the current prevalence of intestinal parasitic infections in schoolchildren of marginal communities of northwestern Mexico and who are periodically treated with albendazole by the national campaign. Results showed that the parasite spp. causing intestinal infections in our study children are not apparently sensitive to the twice yearly administration of albendazole $(400 \mathrm{mg} /$ day). It is well recognized that these infections have multifactorial origin and probably a campaign that administers albendazole combined with 
Table 3. Distribution of eggs of $H$. nana per gram of feces in 133 schoolchildren by age group of 10 public primary schools during 3 sampling periods in northwest Mexico.

\begin{tabular}{|c|c|c|c|c|c|c|}
\hline \multirow[b]{2}{*}{ Age (Years) } & \multicolumn{2}{|c|}{ September 2005} & \multicolumn{2}{|c|}{ September 2006} & \multicolumn{2}{|c|}{ April 2007} \\
\hline & \multicolumn{6}{|c|}{ epg } \\
\hline $6-7.9$ & 21 & $743(354-1100)$ & 18 & $597(270-960)$ & 14 & $955(345-1350)$ \\
\hline $8-9.9$ & 24 & $721(341-1232)$ & 17 & $695(275-1054)$ & 22 & $1265(250-2150)$ \\
\hline $10-11.9$ & 5 & $1436(543-2143)$ & 7 & $604(345-1450)$ & 5 & $900(743-1674)$ \\
\hline
\end{tabular}

CI: Confidence interval.

other antiparasitic drug and accompanied with educational strategies may provide major benefits to the children of this study.

\section{ACKNOWLEDGEMENTS}

Authors thank to the Q.B. Carmen Maria Lugo Flores in formatting the manuscript for the journal. This work was based on the knowledge and contribution of my Professors DWT Crompton and Stephen Phillips. We also thank the primary schools, academic staff, schoolchildren and the financial support granted by CONACYT (Funds SON2004-C01-005 MIXTOS) and the Secretaria de Educación Pública Estatal.

\section{REFERENCES}

[1] Albonico, M., Crompton, D.W. and Savioli, L. (1999) Control strategies for human intestinal nematode infections. Advances in Parasitology, 42, 277-341. doi:10.1016/S0065-308X(08)60151-7

[2] Crompton, D.W. (1999) How much human helminthiasis is there in the world? The Journal of Parasitology, 85, 397-403. doi: $10.2307 / 3285768$

[3] Brown, K.H., Gilman, R.H., Khatun, M. and Ahmed, G. (1980) Absorption of macronutrients from a rice-vegetable diet before and after treatment of ascariasis in children. American Journal of Clinical Nutrition, 33, 1975-1982.

[4] Solomons, N.W. (1993) Pathways to the impairment of human nutritional status by gastrointestinal pathogens. Parasitology, 107, S19-S35.

[5] WHO (1996) Informal consultation on the use of chemotherapy for the control of morbidity due to soil-transmitted nematodes in humans. Division of Control of Tropical Diseases, Geneva.

[6] National System of Health Information (acronym in spanish SINAIS) (2005) Health indicators. The ten major causes of mortality in preschool children in 2005. http://www.sinais.salud.gob.mx/basesdedatos/index.html

[7] Martuscelli, Q.A. (1987) Frequency of helminth infections in children of Mexico. Rev Mex Ped, 36, 111.

[8] Velasco, C., Escobar, G. and Valdespino, G. (1993) Epidemiology of intestinal helminth infections in Mexico: Control basis. National Institute of Diagnosis of Epidemi- ological References, Mexico, DF.

[9] Tay, J., Ruiz, A., Sanchez Vega, J.T., Romero-Cabello, R., Robert, L. and Becerril, M.A. (1995) Intestinal helminthiasis in the Mexican Republic. Boletin Chileno de Parasitologia, 50, 10-16.

[10] Valencia, M.E., Astiazarán, H., Grijalva, M.I., Benítez, M., Saucedo, S., Cervera, A.G., Zazueta, P., Rodriguez, H., Romero, D. and Leon, J. (1995) Assessment and diagnosis of the nutritional status of the Yaqui Indians. Center of Research for Food and Development, Hermosillo.

[11] Higuera, I. (1980) Nutritional survey in the sierra region of the State of Sonora. Research Institute and Superior Learning of Northwestern, Hermosillo.

[12] Morales-Espinoza, E.M., Sanchez-Perez, H.J., GarciaGil Mdel, M., Vargas-Morales, G., Mendez-Sanchez, J.D. and Perez-Ramirez, M. (2003) Intestinal parasites in children, in highly deprived areas in the border region of Chiapas, Mexico. Salud Pública de México, 45, 379-388. doi:10.1590/S0036-36342003000500008

[13] SS (2006) Report of new cases of diseases in the State of Sonora. Statistical and Evaluation Department. Plan- ning and Development Department, Hermosillo.

[14] Hermida, R.C., Ayala, D.E. and Arroyave, R.J. (1995) Comparative circannual pattern in the incidence of giardiasis in different states of Mexico. Bioquimia, 20, 279289.

[15] Gomez, R.N., Mada, V.J., Durazo, G.N., Matty, O.M., Vazquez, P.E. and Robles, M.G. (1996) Helminth infections in children. Report of 543 cases. Clinical Bulletin of the Child Hospital of the State of Sonora (acronym in spanish HIES), 13, 30-34.

[16] National Institute of Statistical and Geography (acronym in spanish INEGI) (2011) Statistical perspective Sonora. National Institute of Statistical and Geography (acronym in spanish INEGI), Aguascalientes, 2011.

[17] Alvarez, G., Lara, F., Harlow, S.D. and Denman, C. (2009) Infant mortality and urban marginalization: A spatial analysis of their relationship in a medium-sized city in northwest Mexico. Pan American Journal of Public Health, 26, 31-38.

[18] Ministry of Education and Culture (acronym in spanish SEC) (2005) Report of enrolled school children in the school year 05-06 in the public elementary schools of the State of Sonora. Sonora. 
[19] Markell, E. and Voge, M. (1976) Medical parasitology. 4th Edition, WB Saunders, Philadelphia.

[20] Cheng, X.J., Yoshihara, E., Takeuchi, T. and Tachibana, H. (2004) Molecular characterization of peroxiredoxin from Entamoeba moshkovskii and a comparison with Entamoeba histolytica. Molecular and Biochemical Parasitology, 138, 195-203.

doi:10.1016/j.molbiopara.2004.08.009

[21] Tay, J., Salazar-Schettino, P.M., De Haro Arteaga, I. and Bucio Torres, M.I. (1976) Incidence of intestinal helminthiasis in Mexico. Revista de Investigacion en Salud Publica, 36, 241-280.

[22] Bayona, A., Andraca, D., Guerrero, T., Hernandez and Tarin, P. (1968) Parasitoscopic studies in Puebla City. Microbiology and Parasitology Latinoamerican Journal, 10, 41-47.

[23] Del Villar Ponce, J.P., Alvarez-Chacon, R. and PerezAmador, N. (1978) Incidence of intestinal parasitosis in children treated at the Clinical Hospital No 68 of IMSS, Tulpetlac, State of Mexico. Salud Publica de Mexico, 20, 93-97.

[24] Guerrero, T.A. (1983) Frequency of intestinal parasitoses in a secondary school. Salud Publica de Mexico, 25, 389392.

[25] Duarte-Zapata, L., Escalante-Triay, F. and Lopez-Novelo De Ceballos, M. (1984) Prevalence of intestinal parasitosis in the middle-class population of the city of Merida. Gaceta Médica de México, 120, 193-197.

[26] Salazar Schettino, P.M., Garcia Yanez, Y., Ruiz Hernandez, A.L., Alonso Guerrero, T., Quintero Garcia, M.E., De Auajare Cinta, S.V. and Rodriguez Ramos, M.G. (1981) Incidence of intestinal parasitoses in populations of the southern region of the Federal District. Salud Publica de Mexico, 23, 179-182.

[27] Guevara, Y., De-Haro, I., Cabrera, M., Garcia, G. and Salazar-Schettino, P.M. (2003) Enteroparasitoses in Indigenous and Mestizo Individuals from the Nayarit Mountain Range, Mexico. Parasitologia Latinoamericana, 58, 30-34.

[28] Gutierrez-Rodriguez, C., Trujillo-Hernandez, B., MartinezContreras, A., Pineda-Lucatero, A. and Millan-Guerrero, R.O. (2007) Frequency of intestinal helminthiasis and its association with iron deficiency and malnutrition in children from western Mexico. Gaceta Médica de México, 143, 297-300.

[29] Martínez, B.I., Vázquez, T.O., Fernández, P.A.M. and Campos, R.T. (1998) Amoebiasis in children of the municipality of Iztapalapa, Federal District, Mexico. Acta Paediatrica of Mexico, 19, 225.

[30] Rodríguez, G.R. and Sánchez-Maldonado, M.I. (1997) Frequency of parasitism in children of Minatitlán, Veracruz. Journal of Medicine Faculty of the National Autonomous University of Mexico (acronym in spanish UNAM), 40, 170-171.

[31] Sánchez De La Barquera, M.I. and Miramontes-Zapata, M. (2011) Intestinal parasitism in 14 rural communities of highlands of Mexico. Mexican Journal of Clinical Pathology, 58, 16-25.

[32] Khosrow, T., Habib, M., Shahla, K., Baratali, R. and Afshin, B. (2011) Prevalence intestinal parasitic infections among primary school attending students in BarandoozChay rural region of Urmia, West Azerbaijan providence, Iran in 2008. African Journal of Microbiology Research, 5, 788-791. 